\section{A progressão temática em Língua Portuguesa: uma análise de notícias sobre a operação Lava Jato no jornal Folha de São Paulo}

\author{
The thematic progression \\ in portuguese language: \\ an analysis of news about \\ 'Lava Jato' operation in the \\ newspaper folha de São Paulo
}

Izabel Larissa Lucena SILVA (UNILAB) izabel_larissa@unilab.edu.br

Fábio Fernandes TORRES (UNILAB) fabioftorres@unilab.edu.br

Carlla Gabriella Ferreira BRASIL (UNILAB) brasil.unilab@gmail.com

Recebido em: 03 de abr. de 2018. Aceito em: 27 de jun. de 2018.
SILVA, Izabel Larissa Lucena; TORRES, Fábio Fernandes; BRASIL, Carlla Gabriella Ferreira. A progressão temática em Língua Portuguesa: uma análise de notícias sobre a operação Lava Jato no jornal Folha de São Paulo. Entrepalavras, Fortaleza, v. 8, n. esp., p. 169-188, set. 2018

Resumo: Este artigo tem por objetivo analisar a manifestação do Tema em notícias que tratam da operação Lava Jato, com o propósito de identificar os tipos de participantes que ocorrem com mais frequência como ponto de partida da oração e os tipos de estratégias de tematização predominantes nas notícias analisadas. Nosso referencial teórico apoia-se na perspectiva teóricometodológica da Gramática SistêmicoFuncional de Halliday e Matthiessen (2004) e no Princípio de Marcação de Givón (1990, 1995). Embora constituam propostas teóricas distintas, tais perspectivas não são excludentes; ao contrário, complementam-se no que diz respeito aos objetivos deste trabalho, que procura investigar o Tema como estratégia textual-discursiva na construção da orientação argumentativa do texto, considerando a correlação motivada entre fatores cognitivos, textual-discursivos e estruturais. Metodologicamente, foram analisadas dez notícias sobre a operação Lava Jato, extraídas do jornal Folha de São Paulo, publicadas entre maio de 2016 a junho de 2017. Os resultados indicam (a) a dominância das entidades humanas "investigado" e "juiz", como ponto de partida da oração nos textos analisados, 
v. 8 (esp.)

169-188 set. 2018

revelando o modo como o autor do texto deseja orientar a interpretação do leitor/ ouvinte sobre a operação Lava Jato e (b) a tematização linear como o tipo de organização da informação mais comum nas notícias investigadas.

Palavras-chave: Tema. Estratégias de Tematização. Operação Lava Jato. Gramática Sistêmico-Funcional. Princípio da Marcação.

Abstract: The purpose of this article is to analyze the manifestation of the Theme in news that deal with the Lava Jato operation, with the purpose of identifying the types of participants that occur most frequently as the starting point of the prayer and the types of thematic strategies that predominate in the analyzed news. Our theoretical reference is based on the theoretical-methodological perspective of the Systemic-Functional Grammar of Halliday and Matthiessen (2004) and on the Markeness Principle of Givón (1990, 1995). Although they constitute distinct theoretical proposals, such perspectives are not exclusive; on the contrary, they are complementary in concerning to the objectives of this work, which seeks to investigate the theme as a textual-discursive strategy in the construction of the argumentative orientation of the text, considering the motivated correlation between cognitive, textual-discursive and structural factors. Methodologically, ten news on the operation Car Wash were analyzed, extracted from the newspaper Folha de São Paulo, which were published between May 2016 and June 2017. The results indicate (a) the dominance of the human entities "investigated" and "judge", as a point of starting from the sentence in the texts analyzed, revealing how the author of the text wishes to guide the interpretation of the reader / listener on the operation Car Wash and (b) the linear thematization as the type of information organization most common in the investigated news.

Keywords: Theme. Thematic Strategies. Operation Car Wash. Systemic-Functional Grammar. Markeness Principle.

\section{Introdução}

A noção de Tema foi estabelecida por Mathesius, que, contrariando a investigação tradicional da oração como uma unidade formal (sintática), passou a concebê-la como uma unidade informacional (contextual-pragmática). Assim, sob tal perspectiva, a oração foi dividida em duas unidades informacionais: o Tema (informação Dada) e o Rema (informação Nova).

Motivado pelas contribuições da Escola Linguística de Praga, Halliday incorporou a noção de Tema à Gramática Sistêmico-Funcional. Todavia, o conceito de Tema para Halliday difere da concepção de Tema estabelecida por Mathesius. Para o linguista britânico, o Tema é o ponto de partida da oração, ou seja, o primeiro elemento da oração que exerce função ideacional, podendo ser, do ponto de vista informacional, uma informação Dada ou Nova.

Neste trabalho, adotamos os pressupostos teórico-metodológicos da Linguística Sistêmico-Funcional e as contribuições do Funcionalismo NorteAmericano, no que diz respeito ao Princípio da Marcação, proposto por Givón (1990, 1995). Concebemos, apoiados em Halliday e Matthiessen (2004), o Tema como o 
elemento quefunciona como pontodepartidada oração. Segundo essaperspectiva funcionalista, a estrutura temática pode ser compreendida como uma importante estratégia textual-discursiva responsável pela orientação argumentativa, isto é, tem relação com o modo como o autor/falante deseja orientar a interpretação do leitor/ouvinte no que diz respeito aos efeitos de sentido pretendidos no texto. Em se tratando do princípio da marcação, propomos analisar as categorias em perspectiva escalar, uma vez que, a depender do contexto discursivo, uma categoria pode ser marcada em um contexto e não marcada em outro, em vez de analisá-las de forma binária, como marcadas ou não marcadas.

Analisamos a progressão temática em notícias que tratam da operação Lava Jato, coletadas no Jornal Folha de São Paulo, entre 2016 e 2017. Para tanto, consideramos, em nossa análise, os tipos de participantes (participantes humanos, participantes não humanos, processos e circunstâncias), que, tomados como ponto de partida da oração, orientam a perspectiva argumentativa do texto.

Nosso propósito, neste artigo, é identificar as estratégias de tematização que predominam nas notícias coletadas, com vistas a investigar os efeitos de sentido produzidos por tais escolhas, uma vez que, para Halliday e Matthiessen (2004), as unidades linguísticas não significam isoladamente, mas estão conectadas e refletem as escolhas operadas pelo autor/falante em relação à rede de opções disponível no sistema.

Para isso, discutimos, nesta introdução, os objetivos gerais do trabalho e o tema a ser desenvolvido; em seguida, apresentamos uma seção que trata dos pressupostos da Gramática Sistêmico-Funcional e do princípio de marcação, segundo Givón (1990, 1995) e uma seção metodológica, que descreve os procedimentos metodológicos adotados e as categorias de análise; posteriormente, analisamos e discutimos os resultados, com base no referencial teórico adotado e nas categorias de análise e, por fim, nas conclusões, retomamos os resultados alcançados.

\section{Pressupostos fundamentais da Gramática Sistêmico-Funcional}

A Linguística Sistêmico-Funcional (LSF) é uma teoria que visa a compreender o funcionamento da linguagem em termos de suas funções comunicativas ${ }^{1}$. Como tal, assume que a descrição do sistema linguístico

\footnotetext{
${ }^{1}$ Como nosso propósito não é rediscutir, reapresentar ou introduzir o modelo teórico da GSF de Halliday e Matthiessen, tampouco o princípio da marcação, de Givón (1990, 1995), o que poderia figurar como enfadonho ao leitor familiarizado com tais referenciais teóricos, procuramos ser sucintos na apresentação do modelo, mormente no que interessa aos propósitos da discussão, razão pela qual não nos estendemos nesta seção.
} 
v. 8 (esp.)

169-188 set. 2018

só pode ocorrer tendo em vista as necessidades comunicativas dos seres humanos nos diferentes contextos de uso da língua.

Sob esse aparato teórico-metodológico da Gramática SistêmicoFuncional (GSF), a língua é vista como um sistema potencial de significados (porque paradigmático) cujos componentes estão interligados e sobre o qual o autor/falante opera suas escolhas segundo seus propósitos comunicativos. O resultado dessas escolhas é o texto, visto, ao mesmo tempo, como lugar de instanciação do sistema ("janela" para o sistema) e forma linguística de interação verbal (GOUVEIA, 2009).

Para Halliday e Matthiessen (2004), uma gramática funcional deve objetivar descrever as expressões linguísticas como padrões léxicogramaticais contextualmente motivados. Assim, a GSF é, segundo Gouveia (2009), simultaneamente, uma gramática do sistema e uma gramática do texto. É apenas por meio do texto que se pode chegar ao sistema, e o principal objetivo da investigação linguística é "lançar luz" sobre o texto. A análise linguística deve revelar, portanto, por que um texto significa o que significa e se ele atinge, efetivamente, ou não, seus propósitos comunicativos.

Considerando que são os propósitos comunicativo-sociais que regem o funcionamento da linguagem, Halliday e Matthiessen (2004) postulam que a estrutura gramatical das línguas tem natureza multifuncional, ou seja, um mesmo item léxico-gramatical pode exercer, ao mesmo tempo, diferentes funções comunicativas. Embora a linguagem se preste a uma variedade de funções, os autores consideram três funções fundamentais envolvidas no uso linguístico: a função ideacional, relacionada ao modo como construímos nossa experiência no mundo; a função interpessoal, relacionada ao modo como estabelecemos/ mantemos nossas relações sociais; a função textual, por meio da qual codificamos significados ideacionais e interpessoais na forma de textos.

A metafunção ideacional tem relação com a necessidade de exteriorização de nossas experiências no mundo. Tais experiências podem estar ligadas ao mundo exterior (material) ou ao mundo interior (de nossa consciência). Na perspectiva da metafunção ideacional, a oração é compreendida como a representação de eventos, ações, processos e relações. O sistema de Transitividade é responsável por fornecer a opções léxicogramaticais envolvidas nesse uso da linguagem. Para Halliday e Matthiessen (2004), a transitividade diz respeito a uma propriedade da oração como um todo, vista como a realização de escolhas entre processos (material, mental, relacional, comportamental, verbal, existencial), participantes (geralmente, sintagmas nominais) e circunstâncias (geralmente, sintagmas adverbiais). 
A metafunção interpessoal se refere à nossa necessidade de estabelecer relações sociais. Por meio dessa metafunção, definimos nosso lugar na interação e manifestamos opiniões, julgamentos e avaliações, indicando as funções da fala em declarações, perguntas, ofertas e comandos. Na perspectiva da metafunção interpessoal, a oração é vista como troca de bens ou serviços ou de informações.

Conforme Halliday e Matthiessen (2004), na troca de bens ou serviços, empregamos a linguagem para controlar/influenciar o comportamento do outro. Nesse caso, a função semântica da oração é a proposta. Na troca de informações, utilizamos a linguagem para trocar informações, isto é, acrescentar uma informação ao nosso interlocutor ou substituir uma informação por outra. A função semântica da oração, na troca de informações, é a proposição. Os recursos léxico-gramaticais concernentes à metafunção interpessoal são fornecidos pelo sistema de Modo. Esse sistema subdivide a oração em Modo Oracional (Sujeito elemento responsável pela proposição - e Finito - elemento responsável pelas relações modais e temporais da proposição) e Resíduo (Predicador, Complemento e Adjuntos).

A metafunção textual tem relação com a organização dos significados ideacionais e interpessoais na forma de textos. Nessa perspectiva, a oração é vista como mensagem. No componente textual, atuam dois subsistemas que funcionam interligados: o sistema da Estrutura de Informação (informação Dada e informação Nova) e o sistema da Estrutura Temática (Tema e Rema).

\section{Tema: concepção e tipos}

Para Halliday e Matthiessen (2004), a Estrutura Temática diz respeito aos recursos léxico-gramaticais responsáveis pela organização da oração enquanto mensagem. Nessa perspectiva, a mensagem pode ser subdividida em dois elementos essenciais complementares: o Tema e o Rema.

O Tema é o ponto de partida da oração, e o Rema é a parte que desenvolve o Tema. Segundo os autores, a definição de Tema não se confunde com a noção de Dado-Novo: a noção de Tema é posicional, uma vez que corresponde ao elemento que aparece primeiro na oração, podendo ser codificado por meio de um sintagma nominal, adverbial ou preposicional; a noção de Dado-Novo é informacional-contextual, pois se liga àquilo que o autor/falante - leitor/ouvinte compartilham em termos de informação no momento da interação. 
v. 8 (esp.)

169-188 set. 2018

Em relação aos tipos de Tema, Lima-Lopes e Ventura (2008) explicam que as unidades selecionadas para ocuparem a posição de Tema têm relação com o modo da oração, ou seja, com o fato de a oração está na forma declarativa (afirmativas/negativas), interrogativa (do tipo sim/não ou do tipo QU-interrogativo), exclamativa (QU-exclamativo) ou imperativa.

Tendo em vista essa distinção, os tipos de Tema, para Halliday e Matthiessen (2004, p. 73), podem ser classificados em dois subtipos: não marcado e marcado. O Tema não marcado, na oração declarativa, por exemplo, é o sujeito. O Tema marcado, por outro lado, é sempre um elemento diferente do sujeito, podendo ser, por exemplo, um sintagma adverbial ou preposicional. Pode ser também um sintagma nominal objeto direto, deslocado para a posição de sujeito.

No que concerne à manifestação do Tema, essa questão não é um ponto pacífico, uma vez que o elemento escolhido para ocupar a posição de Tema pode ser marcado em um contexto e em outro não, como prevê o princípio da marcação proposto por Givón (1990, 1995).

Segundo Givón (1990, 1995), o princípio da marcação manifesta-se nas línguas naturais do seguinte modo: a categoria marcadaéestruturalmente mais complexa, ao passo que a categoria não marcada é estruturalmente mais simples. Esse princípio associa-se, também, à frequência de uso das categorias, nos diversos contextos de comunicação, de modo que as formas mais frequentes são categorias não marcadas, e as formas menos frequentes são marcadas. Desse modo, o princípio da marcação é desdobrado em três subprincípios: a) o subprincípio da complexidade estrutural - a estrutura marcada tende a ser mais complexa (ou maior) do que a não marcada; (b) o subprincípio da distribuição de frequência - a categoria marcada tende a ser menos frequente do que a não marcada e c) o subprincípio da complexidade cognitiva - a categoria marcada tende a ser cognitivamente mais complexa, isto é, exige maior atenção ou maior esforço para seu processamento do que a categoria não marcada.

\section{Estratégias de tematização}

Para a análise da progressão temática, é essencial que se considere as diferentes formas de organização textual. Dănes (apud KOCH, 2015, p. 152) postula cinco diferentes formas de organização temática: progressão temática linear, progressão temática com tema constante, progressão com tema derivado, progressão temática por subdivisão do rema e progressão com salto temático².

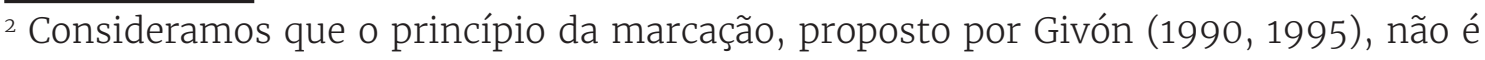


A progressão temática linear ocorre quando o Rema de cada oração passa a funcionar como Tema na oração subsequente. No Tema constante, o Tema se mantém constante, inalterado. Nesse caso, apenas o Rema é modificado. Na progressão com Tema derivado, Temas parciais derivam de um hipertema. A progressão temática por subdivisão do Rema manifesta-se quando vários Temas se originam de um Rema múltiplo, superordenado. A progressão com salto temático é uma espécie de Tema linear. Nessa situação, o falante omite uma oração, que, embora não explicitada, é facilmente inferida pelo contexto.

\section{Procedimentos de constituição e de caracterização do corpus e das categorias de análise}

As notícias utilizadas neste trabalho foram retiradas do portal virtual do jornal Folha de São Paulo. Fazem parte de nosso corpus de análise dez (10) notícias sobre a operação Lava Jato³, coletadas entre maio de 2016 a junho de 2017, conforme o quadro abaixo:

Quadro 1 - Notícias selecionadas

\begin{tabular}{|c|l|c|c|}
\hline \multicolumn{1}{|c|}{ Título da notícia } & \multicolumn{1}{|c|}{$\begin{array}{c}\text { Data de } \\
\text { publicação }\end{array}$} & $\begin{array}{c}\text { Quant. de } \\
\text { ocorrências / } \\
\text { percentual }\end{array}$ \\
\hline $\mathbf{0 1}$ & $\begin{array}{l}\text { Lava Jato mira advogado amigo do ex- } \\
\text { presidente Lula. }\end{array}$ & $19 / 06 / 2017$ & $48 / 14,73 \%$ \\
\hline $\mathbf{0 2}$ & $\begin{array}{l}\text { Defesa de Lula vê elo suspeito da Lava Jato } \\
\text { com EUA. }\end{array}$ & $23 / 11 / 2016$ & $32 / 9,81 \%$ \\
\hline $\mathbf{0 3}$ & $\begin{array}{l}\text { Genro de novo presidente do BNDES é } \\
\text { lobista investigado na Lava Jato. }\end{array}$ & $30 / 05 / 2017$ & $15 / 4,6 \%$ \\
\hline $\mathbf{0 4}$ & $\begin{array}{l}\text { Eduardo Cunha contrata novo advogado } \\
\text { para defesa na Lava Jato. }\end{array}$ & $16 / 06 / 2017$ & $33 / 10,12$ \\
\hline $\mathbf{0 5}$ & $\begin{array}{l}\text { Para Janot, críticos da Lava Jato querem } \\
\text { 'defender amigos poderosos'. }\end{array}$ & $19 / 06 / 2017$ & $26 / 7,97 \%$ \\
\hline
\end{tabular}

incompatível com uma análise que tenha como base o modelo teórico da GSF, uma vez que avalia as categorias em marcadas e não marcadas, considerando-se as situações de uso, o grau de formalidade dos discursos etc., apresentando-se como um princípio cognitivo-comunicativo de natureza universal nas línguas naturais. Como o propósito é identificar as estratégias de tematização que predominam nas notícias coletadas, com vistas a investigar os efeitos de sentido produzidos por tais escolhas, a análise da frequência dessas escolhas é enriquecida quando confrontada com o princípio da marcação. Por outro lado, empregamos as estratégias de progressão temática proposta por Dănes, como categorias de análise, posto que são de suma importância para se compreender a progressão temática nos textos. A frequência de cada estratégia será analisada com base nas metafunções de Halliday e no princípio da marcação de Givón.

3 "Lava Jato" é o nome dado à operação do Ministério Público Federal que investiga casos de corrupção e lavagem de dinheiro, envolvendo empreiteiras e agente públicos. 
v. 8 (esp.) 169-188 set. 2018

\begin{tabular}{|c|l|c|c|}
\hline $\mathbf{0 6}$ & $\begin{array}{l}\text { Delação de Cunha será 'casada' com a do } \\
\text { operador Funaro. }\end{array}$ & $06 / 07 / 2017$ & $26 / 7,97 \%$ \\
\hline $\mathbf{0 7}$ & $\begin{array}{l}\text { Lava Jato em SP vira 'briga de par ou ímpar' } \\
\text { entre juízes. }\end{array}$ & $30 / 05 / 2017$ & $62 / 19,01 \%$ \\
\hline $\mathbf{0 8}$ & $\begin{array}{l}\text { Tribunal reverte decisão de Moro e absolve } \\
\text { Vaccari na Lava Jato. }\end{array}$ & $27 / 06 / 2017$ & $38 / 11,65 \%$ \\
\hline $\mathbf{0 9}$ & $\begin{array}{l}\text { Lava Jato pede que nova procuradora-geral } \\
\text { continue combate à corrupção. }\end{array}$ & $30 / 06 / 2017$ & $28 / 8,58 \%$ \\
\hline $\mathbf{1 0}$ & $\begin{array}{l}\text { Tribunal nega recurso e mantém Vaccari } \\
\text { preso na Lava Jato. }\end{array}$ & $05 / 07 / 2017$ & $18 / 5,52 \%$ \\
\hline
\end{tabular}

Fonte: elaborado pelos autores.

Após a coleta dos textos no portal do jornal Folha de São Paulo, separamos as orações de cada texto, enumerando-as. Para facilitar a identificação das ocorrências, destacamos em negrito os verbos e sublinhamos as informações temáticas, deixando as remáticas sem alterações. Para nos referirmos às ocorrências, empregamos a seguinte notação: a ordem da notícia, no quadro 01, e o número de ocorrência na referida notícia. Assim, No2OC02, por exemplo, refere-se à notícia 02, ocorrência 02.

Do ponto de vista quantitativo-qualitativo, consideramos as seguintes categorias de análise:

a) Elemento ideacional: participantes humanos (investigador, investigado, delator, advogado e juiz), participante não humanos ${ }^{4}$, processos (material, mental, relacional, comportamental, verbal, existencial) 5 e circunstâncias (tempo, lugar, modo, fonte etc.) (HALLIDAY; MATTHIESSEN, 2004).

b) Tipos de tema: marcado e não marcado (HALLIDAY; MATTHIESSEN, 2004 e GIVÓN, 1990, 1995).

c) Tipo de progressão temática: tema constante, tema linear, tema derivado (hipertema), progressão por subdivisão do rema e progressão por salto temático (DĂNES, 1974 apud KOCH,

\footnotetext{
4 Sintagmas nominais na posição de Tema, que não apresentam o traço semântico humano [-hum].

5 Os processos materiais representam nossa experiência no mundo exterior; são ações que realizamos no mundo físico e que demandam algum tipo de energia. São os processos do fazer. Os processos mentais representam experiências em nosso mundo interior, ligadas à imaginação, ao pensamento e à emoção. São os processos do sentir. Os processos relacionais representam significados ligados à identificação e à classificação. São os processos do ser, ter e pertencer. Servem para caracterizar (atributivos) ou identificar (identificativos) as entidades. Os processos comportamentais se encontram em posição intermediária entre os processos materiais e os mentais, e dizem respeito a ações dos mundos físico e psicológico realizadas simultaneamente. Os processos verbais referem-se aos verbos que expressam o dizer. Os processos existenciais estão entre os processos relacionais e materiais e se relacionam com qualquer tipo de fenômeno que é reconhecido como existente.
} 
2015).

Partimos do princípio, também, de que os tipos de progressão temática propostos por Dănes (1974 apud KOCH, 2015) tendem a flutuar na superfície textual, a depender da esfera comunicativa em que os enunciados circulam e da intencionalidade do autor/falante. Assim, nossa hipótese é a de que a progressão por tema linear seja o elemento mais frequente nas notícias analisadas nesta pesquisa, já que se configura como uma estratégia cognitivamente mais simples para orientar a interpretação/processamento da informação do texto.

\section{Análise e discussão dos dados}

Como vimos, para Halliday e Matthiessen (2004), o Tema é o ponto de partida da oração, e o Rema é a parte que desenvolve o Tema. Por referir-se ao elemento que ocupa a posição inicial de cada oração, o tema pode, morfossintaticamente, realizar-se por um sintagma nominal, adverbial ou preposicional.

Sob o prisma do elemento ideacional que é selecionado para ocupar essa posição, os dados de nosso corpus demonstram a predominância de entidades humanas empregadas como Tema, conforme tabela 01.

Tabela 1 - Elemento ideacional

\begin{tabular}{|l|c|c|}
\hline Categorias Ideacionais & $\mathbf{N}^{\mathbf{0}}$ & $\mathbf{\%}$ \\
\hline Participantes humanos & 217 & 66,6 \\
\hline Participantes não humanos & 63 & 19,3 \\
\hline Circunstâncias & 42 & 12,9 \\
\hline Processos & 4 & 1,2 \\
\hline Total/\% & 326 & 100 \\
\hline
\end{tabular}

Fonte: Elaborada pelos autores.

Foram encontradas 326 ocorrências, das quais 217 (66,6\%) são de "participantes humanos"; 63 (19,3\%) são de "participantes não humanos", ou seja, quando um SN não humano funciona como sujeito da oração; 42 (12,9\%) são de "circunstantes", que são sintagmas adverbiais ou preposicionais relacionados à designação das circunstâncias adverbiais (de tempo, de lugar, de fonte etc.) e 4 (1,2\%) são de "processos". 
v. 8 (esp.)

169-188 set. 2018

O predomínio da entidade semântica 6 "participantes humanos" nas notícias analisadas sobre a operação Lava Jato põe em relevo as entidades humanas responsáveis pela realização dos processos designados na predicação dessas orações. Como a temática das notícias selecionadas trata de casos de corrupção, que envolve agentes públicos e donos de empreiteiras, tomar os agentes humanos como ponto de partida da informação orienta o modo como as notícias devem ser interpretadas/ processadas pelos leitores: há corrupção, mas há combatentes.

Por outro lado, a entidade semântica "processo" mostrouse pouco produtiva nos textos analisados, apresentando a menor frequência de uso. Ao que nos parece, a "corrupção", foco desses textos, configura-se como um "cenário" em que os "atores", os corruptos e os combatentes, alternam-se, na posição de Tema para orientar a interpretação/processamento da informação.

Considerando-se o princípio da marcação, proposto por Givón (1990, 1995), os participantes humanos são a categoria não marcada, ao passo que os circunstantes apresentam-se como a categoria marcada. Como o princípio da marcação, embora esteja ancorado em três subprincípios (frequência, complexidade cognitiva e complexidade estrutural), prevê a classificação binária das categorias (marcada e não marcada), poderíamos analisar cada um dos elementos de modo binário, comparando-se um a um. Contudo, parece-nos mais apropriado apresentar os elementos de modo escalar, em que no topo estaria a categoria não marcada e na base a categoria marcada. Essa escala pressupõe que os elementos comportam-se de modo fluido e, a depender do contexto discursivo, podem migrar para o topo (não marcada) ou para a base (marcada). Propomos a escala para os elementos ideacionais no quadro a seguir.

Quadro 2 - Escala de marcação para os elementos ideacionais

\begin{tabular}{|l|l|}
\hline Elementos ideacionais & Escala de marcação \\
\hline Participantes humanos & -- marcado \\
\hline Participantes não humanos & -+ marcado \\
\hline Circunstantes & +- marcado \\
\hline Processos & ++ marcado \\
\hline
\end{tabular}

Fonte: elaborado pelos autores.

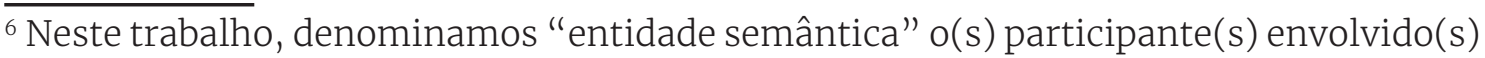
na construção de uma predicação. 
A priori, a escala acima leva em conta somente o subprincípio da frequência. Resta-nos avaliar os elementos ideacionais a partir dos outros subprincípios: a complexidade cognitiva e complexidade estrutural. Ao que nos parece, o subprincípio da complexidade cognitiva atua conjuntamente com o subprincípio da frequência e ambos se sobrepõem ao da complexidade estrutural. No que diz respeito à relação entre cognição e frequência, os participantes humanos figuram como o ponto de partida da informação, porque a natureza do assunto abordado na notícia põe em relevo o juiz, o réu, o delator, o advogado etc., isto é, são termos esperados pelos leitores/ ouvintes como elementos sobre os quais a predicação será construída/ desenvolvida e, portanto, mais fácil e rapidamente interpretada/processada.

Do mesmo modo, devemos considerar que um Tema complexo estruturalmente pode ser, no contexto que estamos analisando, processado cognitivamente sem grande esforço, por processos metonímicos ou metafóricos, tais como: o Ministério Público, a Procuradoria Geral da República, o presidente da empresa investigada, etc. Neste caso, ainda que estruturalmente complexos, esses Temas tendem a ser não marcados, conforme o exemplo a seguir:

(1) A defesa do ex-presidente Luiz Inácio Lula da Silva levantou a suspeita de que a força-tarefa da Operação Lava (No2OCO2).

Por outro lado, os circunstantes tendem a ser cognitiva e estruturalmente complexos; já os processos tendem a ser cognitivamente complexos, embora estruturalmente simples, visto que, ao ocuparem a posição temática, subvertem a ordem canônica da estrutura oracional, conforme exemplos a seguir.

(2) Deacordo com a sentença de primeira instância, foram pagos R\$ 23,4 milhões em propina na Diretoria de Abastecimento da Petrobras (No80C19).

(3) Foram identificados depósitos feitos em 2016 (No1OC34).

As ocorrências (04), (05), (06) e (07), a seguir, exemplificam, respectivamente, as categorias "participantes humanos", "participantes não humanos", "circunstâncias" e "processos":

(4) Cunha está preso em Curitiba desde outubro do ano passado (N4OCO7). 
v. 8 (esp.)

169-188

set.

2018

(5) O sítio Santa Bárbara pertence no papel a Jonas Suassuna e Fernando Bittar, amigos de Fábio Luiz Lula da Silva, filho de Lula (N1OC14).

(6) Na época, Roberto Teixeira disse que jamais combinou "com Alexandrino Alencar ou com qualquer outra pessoa 'forjar' notas fiscais" (N1OC20).

(7) "Foi uma busca do governo americano através da forçatarefa..." (N2OC13).

Observamos que a categoria "participantes humanos" apresentou -se como a categoria não marcada. Cabe, agora, verificar como os elementos dessa categoria comportam-se em relação ao princípio da marcação. A tabela 2, adiante, apresenta o número de ocorrências e o percentual de cada entidade humana encontrada no corpus.

Tabela 2 - Tipo de participante humano

\begin{tabular}{|l|c|c|}
\hline Tipos de participante humano & $\mathbf{N}^{\mathbf{0}}$ & $\mathbf{\%}$ \\
\hline Investigado & 77 & 35,5 \\
\hline Juiz & 55 & 25,3 \\
\hline Investigador & 46 & 21,2 \\
\hline Advogado & 27 & 12,4 \\
\hline Delator & 12 & 5,5 \\
\hline Total/\% & 217 & 100 \\
\hline
\end{tabular}

Fonte: Elaborada pelos autores.

Os dados da tabela 2 revelam que os participantes humanos da subcategoria "investigado" e "juiz" foram os que apresentaram maior número de ocorrências, 77 e 55, respectivamente, que correspondem aos percentuais de $35,5 \%$ e $25,3 \%$ do total das entidades humanas. Essas são as duas categorias que exercem maior impacto na construção da opinião pública sobre a operação Lava Jato: o investigado e o que promove a justiça. Desse modo, a predominância do investigado como Tema põe em destaque o alvo principal das investigações da operação Lava Jato, com o propósito, ao nosso ver, de impactar negativamente na construção da imagem desses indivíduos na sociedade, isto é, são os malfeitores, os criminosos que devem ser combatidos pelo rigor da lei. Por outro lado, temos a alta frequência do participante humano "juiz" como a segunda entidade humana mais recorrente no corpus analisado. De fato, esperávamos menos protagonismo desse elemento nas notícias 
investigadas, já que o juiz não é o agente responsável pela investigação dos casos de corrupção, mas apenas o agente público encarregado de aplicar a pena, conforme a lei. Ao que nos parece, na construção da opinião pública, por meio da mídia em que foram coletadas as notícias, interessa menos o investigador (Ministério Público) e o processo de investigação (acusação de corrupção) que o investigado (burlador da lei) e o juiz (defensor da lei).

Assim, essa relevância da entidade "juiz", em termos de frequência, ante a entidade "investigador", torna-se relevante na elaboração do "conflito" entre dois elementos antagônicos, que se "confrontam" na construção da narrativa dos fatos, ou seja, aquele que faz "justiça" em oposição àquele que comete o crime de corrupção.

Em se tratando do princípio da marcação, em natureza escalar, temos como categorias não marcadas as entidades "o investigado" e "o juiz"; como categoria marcada, a entidade "o delator" e, como categorias intermediárias, "o investigador" e "o advogado", conforme o quadro a seguir.

Quadro 3 - Escala de marcação para os tipos de participantes humanos

\begin{tabular}{|l|l|}
\hline Tipos de participante humano & Escala de marcação \\
\hline Investigado & -- marcado \\
\hline Juiz & -- marcado \\
\hline Investigador & -+ marcado \\
\hline Advogado & -+ marcado \\
\hline Delator & ++ marcado \\
\hline
\end{tabular}

Há de se concordar que todas essas entidades são igualmente importantes para a construção de uma sociedade justa e democrática, contudo, a frequência com que esses termos assumem a posição de Tema revela, nas notícias analisadas, uma orientação argumentativa peculiar na construção da opinião pública sobre o assunto tratado: os elementos mais frequentes, empregados como Tema, mantém-se mais acessível na memória discursiva dos leitores, tornam-se assuntos nas rodas de conversa, e são recebidos como heróis ou vilões. Por outro lado, a figura do delator torna-se pouco relevante (Tema menos frequente, mais marcado), visto que interessa, nesta orientação argumentativa, dar relevância àqueles que agridem a lei e àquele que a defende e pune os agressores (ambos mais frequentes, não marcados). 
v. 8 (esp.)

169-188 set. 2018

Em situação intermediária, estão os elementos "investigador" e "advogado". O protagonismo desses dois elementos está relacionado, ao que nos parece, mais aos elementos que figuram como Tema não marcado que propriamente ao assunto tratado na notícia. A propósito, "o investigador" é um aliado do "juiz", já que, em tese, esclarece todas as instâncias da prática criminal que favorecem a aplicação da pena. Do mesmo modo, "o advogado" desempenha o papel da garantia institucional da lei, de modo que seu cliente, o investigado, seja inocentado, caso não se prove a conduta criminosa, ou receba uma pena justa, nos termos da lei, cuidando para que todo o processo legal seja observado. Sob esse aspecto, o emprego desses elementos como Tema (o investigador e o advogado) pode direcionar uma orientação ora positiva, ora negativa, tanto para "o juiz" quanto para "o investigado", para promover a imagem de "heróis" e "vilões" ou "perseguidor" e "perseguido". Isso pode explicar a posição intermediária desses elementos (o investigador e o advogado) na escala de marcação.

As ocorrências (08) e (09), a seguir, exemplificam, respectivamente, os participantes humanos "investigado" $e$ "juiz":

(8) Lula, segundo o Ministério Público Federal, aceitou o "presente" (No1OC28).

(9) Moro impediu o questionamento por conta de um possível acordo de confidencialidade do delator (N2OC24).

Com relação aos tipos de Tema, Halliday e Matthiessen (2004) distinguem Temas não marcados e marcados. No Tema não marcado, o sujeito (um SN) é o elemento escolhido para configurar na posição de Tema. No marcado, o Tema é um elemento diferente do sujeito, podendo ser, como já dissemos, composto por um sintagma adverbial, um sintagma preposicional, ou um complemento (objeto direto) na posição de sujeito. Cabe observar que essa definição de Halliday e Matthiessen (2004) difere do princípio da marcação proposto por Givón (1990, 1995), visto que eles consideram a concomitância do preenchimento da função de Tema e sujeito da oração para definir o Tema não marcado.

Contudo, em Língua Portuguesa, é mais frequente, de fato, que o sujeito seja tomado como ponto de partida da informação (subprincípio da frequência). Também, é mais comum que o preenchimento dessa posição se dê por sintagmas nominais simples em detrimento de sintagmas estruturalmente complexos (subprincípio da complexidade estrutural). Por 
ser o elemento responsável pela flexão da predicação, o sintagma nominal, na função sintática de sujeito e na função pragmática de Tema, torna uma informação processada de maneira mais natural pelo falante (subprincípio da complexidade cognitiva). Assim, o princípio da marcação, proposto por Givón (1990, 1995), compatibiliza-se com a proposta dos autores.

Para Lima-Lopes e Ventura (2008), a noção de Tema marcado e não marcado pode ser considerada um ponto polêmico na análise do Tema na perspectiva da GSF. Segundo esses autores, há duas possibilidades de interpretação com relação aos casos em que o sujeito da oração não é expresso por um constituinte oracional.

Há autores, como Siqueira (2000) eLima-Lopes (2001), por exemplo, que interpretam a omissão (apagamento) do constituinte sujeito como um caso de Tema marcado, em que o processo (ou verbo) é considerado o Tema da oração, o que satisfaz, segundo os autores, às condições impostas por Halliday (1994) no que diz respeito à presença de um elemento experiencial da sentença como Tema da oração. Já Bárbara e Gouveia (2006) consideram o apagamento do constituinte sujeito como um caso de Tema não marcado, uma vez que a língua portuguesa, diferentemente do inglês que não prevê o sujeito nulo, tem como recurso gramatical a recuperação do sujeito pela desinência do verbo. Na verdade, ao considerar o Tema como uma categoria do texto, os autores demonstram que o Tema, quando está elíptico, pode ser recuperável pelo processo de coesão textual.

Em se tratando da manifestação formal do Tema e considerandose a complexidade da questão, optamos por assumir como Tema não marcado os casos em que o sujeito é implícito ou recuperado pela coesão textual, tal como podemos verificar na ocorrência (10) a seguir:

(10) Em eventos durante a disputa pela PGR, Dodge declarou que a Operação Lava Jato precisa ser mais célere, e (ela Raquel Dodge) defendeu que o combate à corrupção seja a prioridade do órgão (N8OC15).

Na ocorrência (10), o sujeito da oração "defendeu que o combate à corrupção seja a prioridade do órgão" é recuperável, considerando que se trata de orações coordenadas entre si, com sujeitos correferenciais.

A tabela 3, abaixo, apresenta a distribuição dos Temas não marcado e marcado, conforme a proposta de Halliday e Matthiessen (2004). O Tema não marcado teve 239 ocorrências, cuja frequência equivale a 73,3\% e o Tema marcado teve 87 ocorrências, o que corresponde a frequência de $26,7 \%$. 
v. 8 (esp.)

169-188 set. 2018

Tabela 3 - Tema não marcado e marcado.

\begin{tabular}{|l|c|c|}
\hline Tipos de temas & $\mathbf{N}^{\mathbf{0}}$ & $\mathbf{\%}$ \\
\hline Tema não marcado & 239 & 73,3 \\
\hline Tema marcado & 87 & 26,7 \\
\hline Total/\% & 326 & 100 \\
\hline
\end{tabular}

Fonte: Elaborado pelos autores.

Pelo resultado, pode-se afirmar que, nas notícias analisadas, a ordem canônica dos constituintes da oração é a preferida, o que exige menos esforço cognitivo para a interpretação dos enunciados enquanto mensagem. Fica evidente também a preferência dos produtores das notícias, isto é, o modo como desejam orientar a interpretação do leitor/ ouvinte no que se refere à importância/relevância das informações apresentadas. Isso se coaduna com o fato de os participantes humanos, principalmente, "o investigado" e "o juiz", ocuparem, com maior frequência, a posição de Tema, ou seja, são elementos textuais facilmente processados, com o objetivo de manter essa informação sempre disponível e ativada na memória discursiva do leitor.

Desse modo, a se considerar a esfera comunicativa, o assunto tratado e o gênero em que se realizam os textos analisados, segundo a escala de marcação que propusemos anteriormente; na posição de Tema, os participantes humanos figuram como categorias não marcadas; os participantes não humanos e circunstâncias figuram como categorias intermediárias (mais ou menos marcadas) e os processos como categorias marcadas.

As ocorrências (11)e (12), a seguir, exemplificam, respectivamente, um Tema não marcado e um Tema marcado:

(11) A Odebrecht participou das reformas no sítio (N1OC15).

(12) Segundo ele [Janot], esses críticos "empunham estrepitosamente a bandeira do estado de direito, mas desejam mesmo é defender os amigos poderosos com os quais se refestelam nas regalias do poder" (N5OCo8).

Na ocorrência (11), o sujeito é um SN e a oração se encontra na ordem direta (SVO). Em (12), observamos um exemplo de Tema marcado, cuja função sintática é adjunto adverbial (circunstante), isto é, trata-se da fonte da informação que funciona como ponto de partida da oração, o que está relacionado à confiabilidade/credibilidade do conteúdo informacional veiculado. Para Halliday e Matthiessen (2004), a fonte da informação é um tipo de circunstância, o qual eles denominam de "Ângulo" (tipo "Fonte"). 
Em relação às estratégias de tematização, Dănes (1974 apud $\mathrm{KOCH}$, 2015) elenca cinco formas de articulação Tema-Rema: progressão temática linear (rema>tema), progressão temática com tema constante (tema>tema), progressão temática com tema derivado (hipertema), progressão temática por subdivisão do rema (subdivisão do rema) e progressão com salto temático (salto temático).

As ocorrências (13), (14), (15) e (16) abaixo, exemplificam, respectivamente, a progressão linear (Rema > Tema), a progressão com tema constante (Tema>Tema), a progressão com tema derivado (hipertema) e a progressão com salto temático:

(13) A nota da força-tarefa parabeniza Dodge pela indicação ela ainda será submetida à sabatina no Senado. (Rema > Tema) / (N4OCO296/297).

(14) O advogado de defesa, Antônio Augusto Figueiredo Basto, diz que a pena é desproporcional e [ele - o advogado] irá recorrer (Tema>Tema) / (N8OC25).

(15) O ministro do STF (Supremo Tribunal Federal) e presidente do TSE (Tribunal Superior Eleitoral), Gilmar Mendes, disse que a Lava Jato se expandiu demais e que é preciso criticar os "abusos". O magistrado fez referências à investigação do presidente Michel Temer, envolvido na delação da JBS (No50C09).

(16) Costa foi o engenheiro responsável pela obra. O sítio Santa Bárbara pertence no papel a Jonas Suassuna e Fernando Bittar, amigos de Fábio Luiz Lula da Silva, filho de Lula. $\underline{A}$ Odebrecht participou das reformas no sítio (N1OC13).

Na tabela 4, apresentamos os resultados referentes aos tipos de progressão temática encontradas no corpus analisado.

Tabela 4 - Tipos de progressão temática.

\begin{tabular}{|l|c|c|}
\hline Estratégias temáticas & No & $\%$ \\
\hline Rema>Tema & 126 & 57,0 \\
\hline Tema>Tema & 61 & 27,6 \\
\hline Hipertema & 28 & 12,7 \\
\hline Subdivisão do rema & 0 & 0,0 \\
\hline Salto temático & 6 & 2,7 \\
\hline Total/\% & 221 & 100 \\
\hline
\end{tabular}

Fonte: Elaborado pelos autores. 
v. 8 (esp.)

169-188 set. 2018

Pelos dados da tabela 4, percebemos que houve uma frequência maior de uso da estratégia de articulação Rema-Tema, isto é, da progressão temática linear, com 126 ocorrências, o que equivale a 57\%. Esse tipo de articulação linear, em que o Rema da oração passa a funcionar como o Tema da oração subsequente, é um dos mecanismos de coesão textual, e a manifestação do princípio da iconicidade, isto é, da relação icônica entre estrutura temática e estrutura da informação, na superfície textual, em que se parte sempre de uma informação dada para uma informação nova.

Considerando as metafunções ideacional e interpessoal e sua relação com a metafunção textual, no âmbito da progressão temática, a nosso ver, os participantes podem assumir diferentes desdobramentos na progressão temática. A depender do grau de previsibilidade da informação tomada como Tema (dada, nova), da intencionalidade do autor/falante (o jornal) em manter em relevo essa informação, esses elementos tendem a se distribuir, em natureza escalar, em relação ao princípio da marcação. Dessa forma, a distribuição escalar dos participantes humanos é diretamente proporcional ao modo como o autor/falante organiza as suas experiências e sua compreensão de mundo (função ideacional) e como ele deseja influenciar a interpretação das informações veiculadas na notícia pelo leitor/ouvinte (função interpessoal), com o objetivo de orientar a empatia do leitor/ouvinte em relação a esses elementos ideacionais. Como vimos, a escala de marcação para os tipos de elementos ideacionais demonstrou uma preferência, em termos de frequência, pelos elementos "o investigado" e o "o juiz".

\section{Conclusão}

Este trabalho teve como objetivo analisar a manifestação do Tema em notícias do Jornal Folha de São Paulo que tratam da operação Lava Jato, selecionadas entre maio de 2016 a junho de 2017. Para tanto, procuramos identificar os tipos de participantes envolvidos na construção da predicação e sua frequência de ocorrência na posição de Tema, e as estratégias de tematização mais empregadas na composição das notícias. Como suporte teórico-metodológico, utilizamos os postulados da GSF, de Halliday e Matthiessen (2004), e o princípio da marcação, proposto por Givón (1990,1995), fazendo uma interface entre os pressupostos da perspectiva sistêmico-funcional e do funcionalismo norte-americano. 
Os resultados revelaram que, do ponto de vista da metafunção ideacional, a entidade semântica "participantes humanos" ocorre com maior frequência nos textos analisados, configurando-se como a categoria não marcada, tendo sido os agentes "investigado" e "juiz" os mais frequentes. Essa estratégia tem a ver com o modo como o produtor textual deseja orientar/manipular a interpretação do leitor, contrapondo dois elementos ideacionais antagônicos: "corruptor" x "justiceiro".

Os dados também revelaram que a preferência pela ordem direta (canônica) dos constituintes oracionais, com a predominância do Tema não marcado, isto é, codificado por um SN em posição de sujeito, constitui um mecanismo de organização da informação na oração, de forma clara, objetiva e linear. No que diz respeito aos tipos a articulação Tema-Rema, a progressão temática linear foi a mais recorrente, o que configura como uma importante estratégia de sequenciação linear da informação e de construção dos elos coesivos, em que se percebe uma relação icônica entre estrutura temática e estrutura da informação.

Dessa forma, com esta análise, esperamos contribuir com as pesquisas que têm por objetivo investigar a relação entre estratégia de tematização e construção textual-discursiva, haja vista que buscamos analisar como os condicionamentos cognitivos e textual-discursivos governam a distribuição da informação no texto, bem como sua orientação argumentativa, decorrentes do tipo de participante selecionado como ponto de partida da oração.

\section{Referências bibliográficas}

BÁRBARA, L; GOUVEIA, C. A. Marcado ou não marcado não é a questão, a questão é: onde está o tema? In: MOTTA-ROTH, D.; BARROS, N. C. A.; RICHTER, M. G. (Org.). Linguagem, cultura e sociedade. Santa Maria: Universidade Federal de Santa Maria, 2006, p. 57-66.

GOUVEIA, Carlos, A.M. Texto e Gramática: uma introdução à linguística sistêmico-funcional. Matraca, RJ, v. 16, n. 24, p.13-47, jan./jun. 2009.

GIVÓN, T. Functionalism and gramar. Amsterdã: John Benjamins, 1995.

Markeness in Grammar: distributional, communicative and

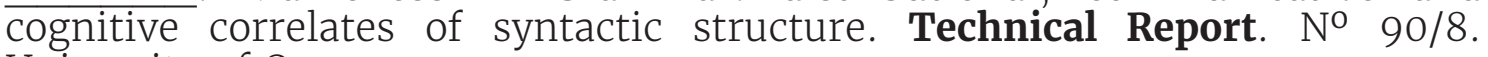
University of Oregon, 1990.

HALLIDAY, M. A. K. An introduction to functional gramar. 2. ed. Londres: Arnold, 1994.

; MATTHIESSEN, C. M. I. M. An introduction to functional gramar.

3. ed. Londres: Arnold, 2004. 
v. 8 (esp.)

169-188

set.

2018
LIMA-LOPES, R.E. Padrões Temáticos em Cartas de Negócios. Trabalho apresentado no $6^{\circ}$ CBLA (Congresso Brasileiro de Linguística Aplicada)

- UFMG, Belo Horizonte, Minas Gerais, Brasil. Mimeo, 2001.

; VENTURA, C. S. M. A transitividade em Português. DIRECT PAPERS, V. 55, p. 1-22, 2008.

KOCH, I. G. V. Desvendando os segredos do texto. 8. ed. São Paulo: Contexto, 2015.

SIQUEIRA, C.P. Análise temática em estudos de tradução: o caso dos relatórios anuais de empresas brasileiras. 2000. 123 f. Dissertação. (Mestrado em Linguística Aplicada) - Programa de Pós-Graduação em Linguística Aplicada e Estudos da Linguagem, PUC-SP, São Paulo, 2000. 